OPEN ACCESS

Edited by:

Antonio Porro,

University of Zürich, Switzerland

Reviewed by:

Mario Cioce,

NYU Langone Medical Center, USA

Karla M. Neugebauer,

Yale University, USA

*Correspondence:

Marianne Farnebo,

Department of Oncology-Pathology,

Cancer Centrum Karolinska,

Karolinska Institutet, CCK R8:04,

17176 Stockholm, Sweden

marianne.farnebo@ki.se

Specialty section:

This article was submitted to Cancer Genetics, a section of the journal

Frontiers in Genetics

Received: 10 December 2014 Accepted: 19 February 2015 Published: 24 March 2015

Citation:

Henriksson S and Farnebo M (2015) On the road with WRAP53;: guardian of Cajal bodies and genome integrity.

Front. Genet. 6:91

doi: 10.3389/fgene.2015.00091

\section{On the road with WRAP53ß: guardian of Cajal bodies and genome integrity}

\author{
Sofia Henriksson ${ }^{1}$ and Marianne Farnebo ${ }^{2 *}$ \\ ${ }^{1}$ Science for Life Laboratory, Division of Translational Medicine and Chemical Biology, Department of Medical Biochemistry \\ and Biophysics, Karolinska Institutet, Stockholm, Sweden, ${ }^{2}$ Department of Oncology-Pathology, Cancer Centrum Karolinska, \\ Karolinska Institutet, Stockholm, Sweden
}

The WRAP53 gene encodes both an antisense transcript (WRAP53 $\alpha$ ) that stabilizes the tumor suppressor p53 and a protein (WRAP53 ) involved in maintenance of Cajal bodies, telomere elongation and DNA repair. WRAP53 $\beta$ is one of many proteins containing WD40 domains, known to mediate a variety of cellular processes. These proteins lack enzymatic activity, acting instead as platforms for the assembly of large complexes of proteins and RNAs thus facilitating their interactions. WRAP53 $\beta$ mediates site-specific interactions between Cajal body factors and DNA repair proteins. Moreover, dysfunction of this protein has been linked to premature aging, cancer and neurodegeneration. Here we summarize the current state of knowledge concerning the multifaceted roles of WRAP53 $\beta$ in intracellular trafficking, formation of the Cajal body, DNA repair and maintenance of genomic integrity and discuss potential crosstalk between these processes.

Keywords: WRAP53, WDR79, TCAB1, Cajal body, telomerase, SMN, scaRNA, DNA repair

\section{Introduction}

The eukaryotic cell nucleus is highly organized with several sub-compartments containing high concentrations of factors involved in specific biological processes to optimize performance. Numerous distinct, non-membrane-bound nuclear bodies, including nucleoli, nuclear speckles, histone locus bodies, promyelocytic leukemia (PML) bodies and Cajal bodies, have been identified and shown to overlap with respect to their components and organization. Formation of such sub-organelles usually involves dynamic processes, such as protein modifications and self-association, various RNA-protein interactions and tethering of central factors to specific gene loci (Dundr and Misteli, 2010; Machyna et al., 2013).

Identified more than a century ago and subjected to intense functional investigation, the Cajal body has been suggested to be associated with telomere maintenance and maturation of the splicing machinery (Machyna et al., 2013). In a similar manner, DNA repair factors are sequestered in specialized repair centers called foci. Following induction of DNA double-strand breaks, a variety of proteins are mobilized to the break sites to initiate the signaling cascades required for proper repair (Polo and Jackson, 2011).

WRAP53 $\beta$ (also denoted WRAP53 or WDR79 or TCAB1), is a scaffold protein that directs factors to Cajal bodies, telomeres and DNA double-strand breaks, thereby facilitating the interactions necessary for appropriate biological responses (Tycowski et al., 2009; Venteicher et al., 2009; Mahmoudi et al., 2010). 
The WD40 domain of WRAP53 $\beta$ appears to be critical for its function, by serving as a scaffold for multiple interactions between a wide variety of molecules. Mutations predicted to impair the structure of this domain cause dyskeratosis congenita, a syndrome associated with premature aging and an elevated predisposition for cancer, highlighting the importance of WRAP53 $\beta$ for homeostasis (Zhong et al., 2011).

In the present review, we focus on WRAP53 $\beta$ and its reported roles in the maintenance of the Cajal body, as a component of the telomerase enzyme and, recently, in DNA damage response and repair. We also discuss the involvement of this protein in various diseases.

\section{WRAP53: One Gene-Multiple Products}

As its name indicates, the WD40-encoding RNA antisense to $\mathrm{p} 53$ (WRAP53) gene, identified in our laboratory, encodes at least two different functional products: an antisense transcript that stabilizes p53 (referred to as WRAP53 $\alpha$ ) and, via alternative transcriptional start site usage, a protein containing WD40 repeats (referred to as WRAP53 $\beta$, alias WRAP53, WDR79 and TCAB1). Moreover, a third alternative start site in exon $1 \gamma$ gives rise to WRAP53 $\gamma$ transcripts overlapping the first intron of p53, the function of which remains elusive and is not discussed further here (Figure 1) (Farnebo, 2009; Mahmoudi et al., 2009; Tycowski et al., 2009; Venteicher et al., 2009).

\section{WRAP53 $\alpha$ : a Natural p53 Antisense Transcript}

The WRAP53 gene on chromosome 17 p13 partially overlaps the $p 53$ tumor suppressor gene in a head-to-head orientation
(Figure 1). This organization has functional consequences, i.e., WRAP53 $\alpha$ transcripts containing this overlap regulate the levels of p53 mRNA and protein.

By binding to the $5^{\prime}$ UTR region of p53 mRNA through a perfectly complementary sequence, WRAP $53 \alpha$ stabilizes this mRNA, thereby promoting induction of the p53 protein in response to DNA damage required for mediating apoptosis (Mahmoudi et al., 2009). The insulator protein CTCF contributes to WRAP $53 \alpha$-mediated regulation of $\mathrm{p} 53$ by binding WRAP $53 \alpha$ RNA (Saldana-Meyer et al., 2014). Several lines of evidence indicate that neither WRAP53 $\beta$ transcripts nor protein are involved in regulating p53: (1) overexpression of the overlapping exon $1 \alpha$, which is not present in WRAP53 $\beta$ transcripts, efficiently elevates the steady-state level of p53: whereas overexpression of exon $1 \beta$ or the WRAP53 $\beta$ protein has no such effect. (2) siRNAs targeting exon $1 \alpha$, but not exon $1 \beta$ down-regulate p53. And (3) knockdown of WRAP $53 \alpha$ transcripts does not alter WRAP $53 \beta$ protein levels, but nevertheless reduces p53 expression (Farnebo, 2009; Mahmoudi et al., 2009).

\section{WRAP53ß: an Essential Cajal Body Component}

Most investigations on the WRAP53 gene have focused on the WRAP53 $\beta$ (WRAP53/WDR79/TCAB1) protein, which is highly evolutionary conserved, with homologs (confined to its WD40 repeats) in vertebrates, invertebrates, plants and yeast. A WD40 repeat is a short structural motif containing approximately 40 amino acids and often a C-terminal tryptophan (W) and aspartic acid (D) dipeptide. Typically multiple WD40 repeats exist within a WD40 domain, which allow interaction with several partners simultaneously, in a nonexclusive manner (Stirnimann et al., 2010; Xu and Min, 2011).

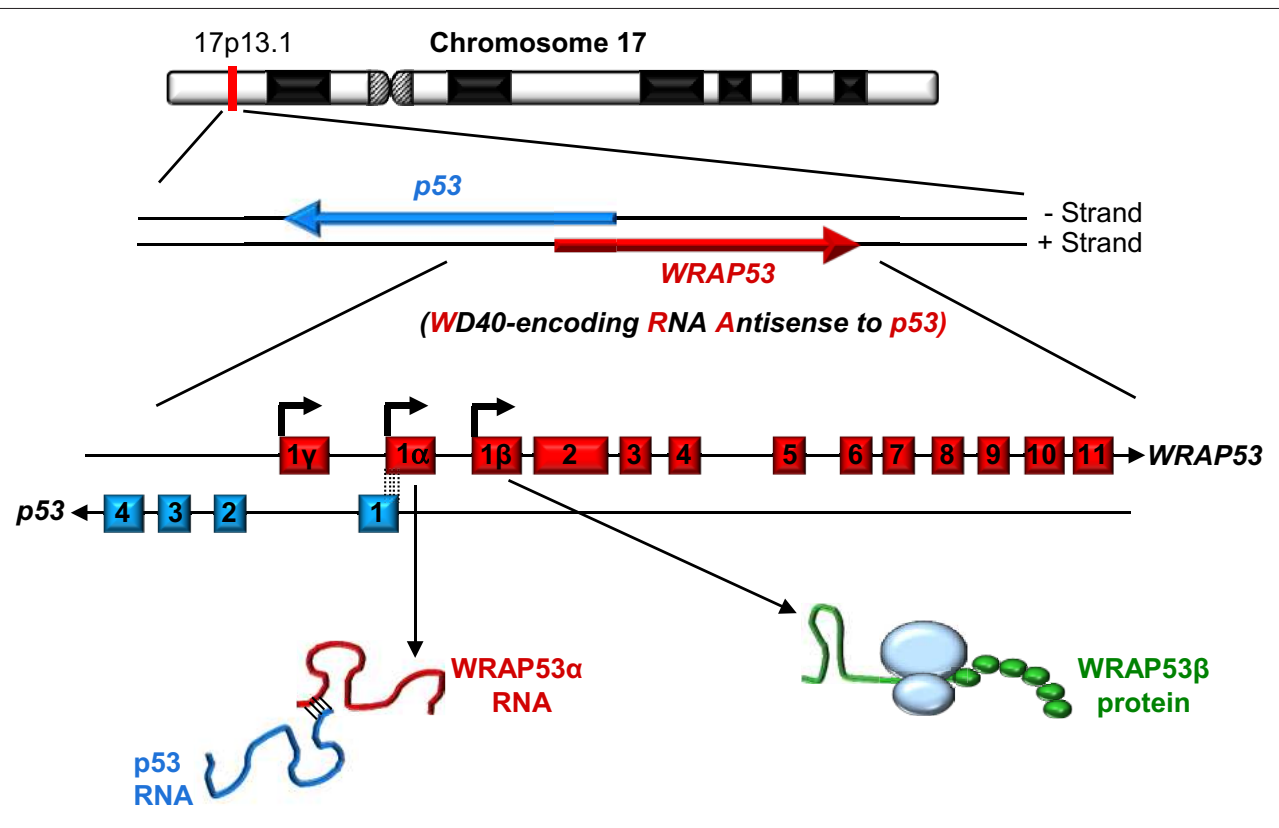

FIGURE 1 | The WRAP53 and p53 genes and their gene products. The arrows indicate the direction of transcription and the dotted lines the exon overlap between these genes. 
WRAP53 $\beta$ consist of a proline-rich N-terminus (16 of 50 residues $=32 \%$ ), a central WD40 domain (predicted to contain 5-7 repeats) and a glycine-rich C-terminus (7 of 13 residues $=54 \%)$ (Figure $2 \mathrm{~A})$.

The WRAP53 $\beta$ protein is found both in the cytoplasm and highly enriched in nuclear organelles known as Cajal bodies (Figure 2B) (Mahmoudi et al., 2010). These spherical organelles $(0.2-2 \mu \mathrm{M})$, were identified and described by Santiago Ramón y Cajal in 1903 (Gall, 2003). Their numbers range from 1 to 10 per nucleus, being highest in cells with rapid rates of transcription and splicing (Cioce and Lamond, 2005; Boulon et al., 2010).

Cajal bodies are characterized by the marker protein coilin that interacts with many factors and thereby serves as a platform for the assembly of Cajal bodies. Cajal bodies are rich in ribonucleoprotein (RNP) complexes, including the spliceosomal small nuclear RNPs (snRNPs), small Cajal body-specific RNPs (scaRNPs), small nucleolar RNPs (snoRNPs) and components of the telomerase RNP complex. Accordingly, Cajal bodies have been described to play essential roles in the maturation of snRNPs and snoRNPs and telomere maintenance. Furthermore, the survival of motor neuron (SMN) complex and factors involved in $3^{\prime}$-end processing of histone mRNA accumulate in these bodies (Carvalho et al., 1999; Machyna et al., 2013). Defects in Cajal body formation are linked to impaired cell proliferation and splicing, but rather than being essential for the associated processes, this compartment is thought to enhance efficiency by concentrating necessary factors in the same space (Lemm et al., 2006; Whittom et al., 2008; Novotny et al., 2011).

Cajal bodies are highly dynamic, moving within the nucleoplasm except when transiently immobilized through interaction with chromatin. These interactions occur at specific loci with repeated clusters of snRNA, U3 snoRNA and histone genes and in a transcription-dependent manner (Frey and Matera, 1995; Gao et al., 1997; Frey et al., 1999; Platani et al., 2000). Tethering experiments have revealed that immobilization of various constituents leads to the de novo formation of Cajal bodies, a self-organized process that appears to occur in random order, without internal hierarchy of individual components (Kaiser et al., 2008; Shevtsov and Dundr, 2011).

Several studies have emphasized the role of WRAP53 $\beta$ as a central player in maintenance of and localization of factors to the Cajal body (Figure 2C). Indeed, without WRAP53 $\beta$ these organelles collapse and cannot re-form. Exogenous WRAP53 $\beta$ accumulates in Cajal bodies, but does not stimulate de novo formation of this organelle. Instead, Cajal bodies are disrupted when high levels of this protein are exogenously expressed, indicating an adverse effect on the function of endogenous WRAP $53 \beta$, potentially via self-association or sequestration of certain factors important for Cajal body formation (Mahmoudi et al., 2010). Similar effects have been observed when coilin is exogenously overexpressed (Hebert and Matera, 2000).

In addition to maintaining their structural integrity, WRAP53 $\beta$ targets several factors to Cajal bodies and loss of this trafficking is associated with various disorders (see further below). Depletion of this protein causes many factors to mislocalize to the nucleolus (Mahmoudi et al., 2010). This may indicate that WRAP53 $\beta$ promotes the translocation of

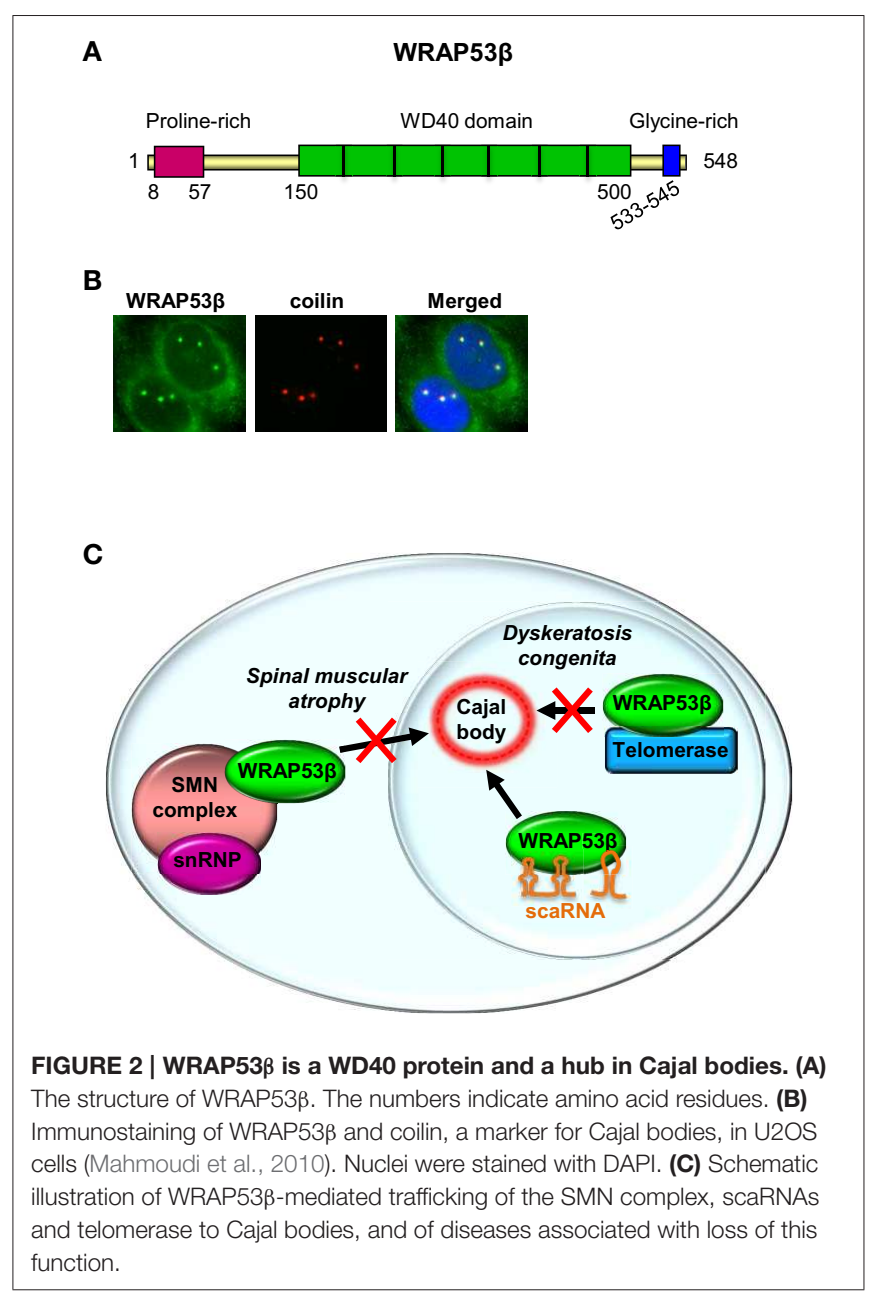

factors from the nucleolus to Cajal bodies or alternatively by binding and directing factors to these bodies, prevents them from accumulating in nucleoli. WRAP53 $\beta$ does not regulate localization of factors to other nuclear organelles, such as gems, splicing speckles and PML bodies (Mahmoudi et al., 2010).

\section{WRAP53 $\beta$ Guides SMN Across the Cell to Cajal Bodies}

One factor, which WRAP53 $\beta$ helps to localize to Cajal bodies, is the SMN protein that together with its partner proteins Gemin28 and Unrip, forms the SMN complex involved in the cytoplasmic assembly of the spliceosomal snRNPs (Gubitz et al., 2004; Chari et al., 2008; Cauchi, 2010; Matera and Wang, 2014). By binding Sm proteins and snRNAs separately, the SMN complex promotes Sm binding specifically to snRNA (Pellizzoni et al., 2002).

WRAP53 $\beta$ is involved in the translocation of SMN across the cell. After binding SMN in the cytoplasm, WRAP53 $\beta$ first recruits this protein to the nucleus by promoting its interaction with the nuclear pore receptor importin $\beta$ and then targets SMN to Cajal bodies by facilitating its interaction with coilin. Thus, knockdown of WRAP53 $\beta$ results in accumulation of SMN in the cytoplasm 
and mislocalization of nuclear SMN to the nucleolus. WRAP53 $\beta$ itself is targeted to Cajal bodies via its WD40 domain and a stretch of its C-terminus, and these same regions appears to scaffold the SMN-coilin interaction (Mahmoudi et al., 2010).

\section{Is the WRAP53 $\beta$ Route Blocked in Spinal Muscular Atrophy?}

Mutations in the SMN1 gene results in spinal muscular atrophy (SMA), a neurodegenerative disorder characterized by progressive degeneration of spinal cord anterior horn $\alpha$-motor neurons and the leading genetic cause of infant mortality with an incidence of approximately 1:6000 live births (Coady and Lorson, 2011). The reason why spinal motor neurons are particularly sensitive to mutations of the SMN protein is not fully understood. Cells lacking SMN display impaired assembly of the snRNP core, along with splicing defects (Fischer et al., 1997; Pellizzoni et al., 2002; Zhang et al., 2008), however, the fact that most human cells require splicing points to additional functions of SMN important for this cell type. In line with such an idea, the nuclear function of SMN remains unclear and the severity of the SMA disease increases as the level of SMN protein and number of SMNcontaining nuclear structures decreases (Lefebvre et al., 1997; Oskoui et al., 2007; Tapia et al., 2012).

Interestingly, defective WRAP53 $\beta$-mediated trafficking of $\mathrm{SMN}$ is observed in patients afflicted by the most severe form of spinal muscular atrophy (type I or Werdnig-Hoffmann disease) (Lefebvre et al., 1997; Oskoui et al., 2007; Mahmoudi et al., 2010; Tapia et al., 2012). This impaired interaction could not be explained by the lower amount of SMN protein present; instead, WRAP53 $\beta$ can apparently not bind properly to SMN and localize SMN to Cajal bodies in these cells (Mahmoudi et al., 2010). Since WRAP53 $\beta$ recently was identified as an important regulator of DNA double-strand break repair (Henriksson et al., 2014), it is possible that SMN collaborates with WRAP53 $\beta$ in this process and that impaired DNA repair contributes to the pathogenesis of SMA.

\section{Another Highway: WRAP53 $\beta$ Targets Scarna to Cajal Bodies}

WRAP53 $\beta$ also guides a class of RNA molecules referred to as scaRNAs to Cajal bodies, which are required for catalyzing post-transcriptional modifications (including pseudouridylation and 2'-O-methylation) of the snRNA component of snRNPs (Tycowski et al., 2009). These modifications are important for their proper incorporation into the spliceosome (Darzacq et al., 2002; Jady et al., 2003).

The scaRNA family consists of at least 20 members, including the RNA component of telomerase (TERC). They are divided into two major classes: the C/D box scaRNAs, which contain the C (RUGAUGA) and D (CUGA) motifs and direct methylation of target snRNAs, and the H/ACA box scaRNAs, which contain the $\mathrm{H}$ (ANANNA) and ACA motifs and guide isomerization of uridine into pseudouridine. The C/D box scaRNAs associate with four core proteins: the methyltransferase fibrillarin, NOP56,
NOP58 and 15.5K/NHPX, while the H/ACA box scaRNAs associate with four other core proteins: the pseudouridine synthase dyskerin, GAR1, NHP2, and NOP10. The RNA components of the scaRNPs direct the enzymes and associated proteins to their target RNAs via sequence complementarity (Kiss, 2002; Kiss et al., 2006).

The scaRNAs are targeted to Cajal bodies by a common element, referred to as the Cajal body localization signal or CAB box. The consensus sequence of this element is: ugAG for H/ACAs scaRNA and GU-rich dinucleotide repeats in the case of C/D box scaRNAs (Richard et al., 2003; Tycowski et al., 2009; Marnef et al., 2014). Although, the factor(s) responsible for this targeting long remained unknown, WRAP $53 \beta$ has now been shown to associate specifically with the CAB box of scaRNAs and promote their targeting to Cajal bodies. Thus, CAB box mutations that disturb binding to WRAP $53 \beta$ or depletion of this protein results in mislocalization of scaRNAs to nucleoli (Tycowski et al., 2009).

Although WRAP53 $\beta$ does not appear to bind snRNAs or snoRNAs that lack CAB box motifs it does bind to another class of RNAs, the AluACA RNAs (Jady et al., 2012). Interestingly, these RNAs originate from Alu repeats, are processed into RNA containing $\mathrm{H} / \mathrm{ACA}$ and $\mathrm{CAB}$ boxes and also associate with dyskerin, NOP10, NHP2 and GAR1. Despite their CAB box motifs, the AluACA RNAs accumulate in the nucleoplasm rather than Cajal bodies and their function is not known.

\section{WRAP53 $\beta$ : the Telomerase Taxi}

The telomerase RNP holoenzyme catalyzes the addition of telomeric repeats TTAGGG onto the ends of linear chromosomes. The minimal catalytic unit consists of a reverse transcriptase (TERT) and the TERC RNA template containing the sequence copied by TERT (Artandi and Depinho, 2010). WRAP53 $\beta$ associates with the TERC CAB box of the enzymatically active telomerase complex and promotes its localization to Cajal bodies (Venteicher et al., 2009). Since TERC is an H/ACA scaRNA, it also binds the scaRNP core proteins dyskerin, GAR1, NHP2 and NOP10 that play important roles in the stability, nuclear localization and proper assembly of telomerase RNP (Artandi and Depinho, 2010). Structural deviations and a lack of complementary target RNAs indicate that TERC is not directly involved in pseudouridylation of snRNAs (Mitchell et al., 1999; Trahan and Dragon, 2009; Egan and Collins, 2012).

The observation that WRAP53 $\beta$ binds all core components of telomerase (including TERC, TERT and dyskerin), but not to telomerase assembly factors (including NAF1, pontin and reptin), indicates that this protein is a component of the active telomerase enzyme. WRAP53 $\beta$ is required for telomerase localization to Cajal bodies, which associate with telomeres during S-phase (Jady et al., 2006; Tomlinson et al., 2006; Venteicher et al., 2009). Knockdown of WRAP53 $\beta$ disrupts targeting of TERC to both Cajal bodies and telomeres and, consequently, leads to progressive telomere shortening. Similarly, cells with TERC containing a $\mathrm{CAB}$ box mutation also display telomere shortening, probably due to mislocalization of TERC to the nucleolus (Venteicher et al., 2009; Egan and Collins, 2010). However, telomerase function and telomere elongation was recently shown 
to be unaffected in Cajal body-deficient coilin knockout cells. This suggest that Cajal bodies not are essential in this process, whereas certain Cajal body factors such as WRAP $53 \beta$ clearly play important roles in telomere homeostasis. Additional studies are required to clarify the previous suggested role for the Cajal body in telomere biology (Chen et al., 2015).

\section{WRAP53 $\beta$ and Dyskeratosis Congenita}

Germline mutations in WRAP53 $\beta$ result in dyskeratosis congenita, a syndrome characterized by bone marrow failure, premature aging, predisposition for cancer and a triad of mucocutaneous features including oral leukoplakia, abnormal skin pigmentation and nail dystrophy (Zhong et al., 2011). This disease is caused by defective telomere maintenance, since approximately $50 \%$ of all cases carry mutations in core components of the telomerase enzyme or in telomere capping proteins, such as TERC, TERT, dyskerin, TIN2 and WRAP53 $\beta$ (Dokal, 2011; Zhong et al., 2011; Ballew and Savage, 2013).

Although patients with dyskeratosis congenita display very short telomeres, clinical characteristics, such as age at onset and disease severity are not strictly correlated to telomere length. Moreover, with certain associated TERT mutations telomerase activity is maintained (Vulliamy et al., 2011; Zaug et al., 2013). Therefore, additional perturbations, such as impaired stem cell function and defects in rRNA processing and DNA repair, might be involved in the etiology of dyskeratosis congenita (Ruggero et al., 2003; Mochizuki et al., 2004; Zhang et al., 2012b; Bellodi et al., 2013).

Mutations in WRAP53 $\beta$ are inherited in an autosomal recessive fashion and reside in highly conserved regions of its WD40 domain. These mutations reduce the nuclear level of WRAP53 $\beta$, impair its trafficking of telomerase to telomeres, and subsequently lead to progressive shortening of telomeres in these patients (Zhong et al., 2011). Recently, the chaperonin CCT/TRiC was identified to be crucial for proper folding of WRAP $53 \beta$ and this folding was found to be impaired in dyskeratosis congenita (Freund et al., 2014). Since mutated and unfolded WRAP53 $\beta$ is not translocated into the nucleus, all of its activities in this organelle should be disturbed.

Interestingly, our group demonstrated recently that WRAP53 $\beta$ is involved in the repair of DNA double-strand breaks (Henriksson et al., 2014), which thus might contribute to disease onset and severity in patients with dyskeratosis congenita. Since this function is independent of telomerase activity, the clinical differences between patients with WRAP53 $\beta$ or TERT/TERC mutations might be due to accumulation of DNA damage. Indeed, mutations in WRAP53 $\beta$ result in a more severe form of this disease (Dokal, 2011; Ballew and Savage, 2013). Similarly, mutations in dyskerin cause a severe variant of dyskeratosis congenita with elevated numbers of $\gamma \mathrm{H} 2 \mathrm{AX}$ foci in response to induction of DNA double-strand breaks. The majority of these foci were not localized to telomeres, suggesting a general enhancement in DNA damage ( $\mathrm{Gu}$ et al., 2008).

\section{WRAP53 $\beta$ Takes a New Route-to DNA Double-Strand Breaks}

Among the most cytotoxic DNA lesions are double-strand breaks, which are repaired by the homologous recombination (HR) or non-homologous end joining (NHEJ) pathways and involves stepwise accumulation of repair proteins at the site of damage. One of the earliest events following DNA double-strand breakage is phosphorylation of the nearby H2AX histone variant on serine-139 (to form $\gamma \mathrm{H} 2 \mathrm{AX}$ ) catalyzed by ATM, ATR, and DNA-PK kinases (Durocher and Jackson, 2001). Next, the adaptor protein $\mathrm{MDC} 1$ binds $\gamma \mathrm{H} 2 \mathrm{AX}$ via its tandem BRCT domain and is subsequently phosphorylated by ATM. MDC1 serves as an anchor for the assembly of a variety of proteins to the site of DNA damage (Stucki et al., 2005), including RNF8, which is the first E3 ligase to be recruited to these breaks. The FHA domain of RNF8 binds to ATM-phosphorylated residues of MDC1 (four TQXF clusters). Via its RING domain, RNF8 then ubiquitylates histones $\mathrm{H} 2 \mathrm{~A}$ and $\mathrm{H} 2 \mathrm{AX}$ at DNA damages sites, which in turn promotes accumulation of downstream factors (Huen et al., 2007; Kolas et al., 2007; Mailand et al., 2007).

The first indication that WRAP53 $\beta$ is involved in the repair of DNA double-strand breaks was its accumulation at such breaks induced by either whole cell or laser micro-irradiation. In a manner dependent on the DNA damage response protein kinase ATM, histone H2AX and MDC1, WRAP53 $\beta$ is rapidly recruited to DNA breaks, reaching maximal levels $1 \mathrm{~h}$ after damage and thereafter gradually declining as the DNA breaks are repaired. Loss of WRAP53 $\beta$ leads to prolonged cell cycle arrest at the G2/M stage following irradiation, as well as more spontaneous DNA breaks, which are considered to be the major cuase of genomic instability (Henriksson et al., 2014). Moreover, in cells depleted of WRAP53 $\beta$ recruitment of repair factors to DNA breaks is impaired and both the HR and NHEJ repair pathways are defective (Henriksson et al., 2014). Mechanistically, WRAP53 $\beta$ target the critical ubiquitin ligase RNF8 to DNA lesions by mediating the interaction with its upstream partner MDC1. WRAP53 $\beta$ binds the FHA domains of both RNF8 and MDC1 simultaneously via its WD40 domain, thereby facilitating accumulation of RNF8 and ubiquitylation at DNA doublestrand breaks (Henriksson et al., 2014). Accordingly, WRAP53 $\beta$ is required for the assembly of downstream repair proteins such as 53BP1, BRCA1, and RAD51 at DNA breaks (Figure 3) (Henriksson et al., 2014).

\section{The Two Faces of WRAP53 $\beta$ in Cancer}

One of the effects of WRAP53 $\beta$ depletion observed earliest was apoptosis of cancer cells in vitro whereas normal cells were unaffected (Mahmoudi et al., 2011). The subsequent finding that WRAP53 $\beta$ is overexpressed in a variety of cancer cell lines of different origins and that such overexpression promotes carcinogenic transformation indicated that this protein possesses oncogenic properties (Mahmoudi et al., 2011). In agreement with this proposal, WRAP53 $\beta$ has been found to be overexpressed in primary nasopharyngeal carcinoma (Sun et al., 2014), esophageal squamous cell carcinoma (Rao et al., 2014) and rectal cancer 


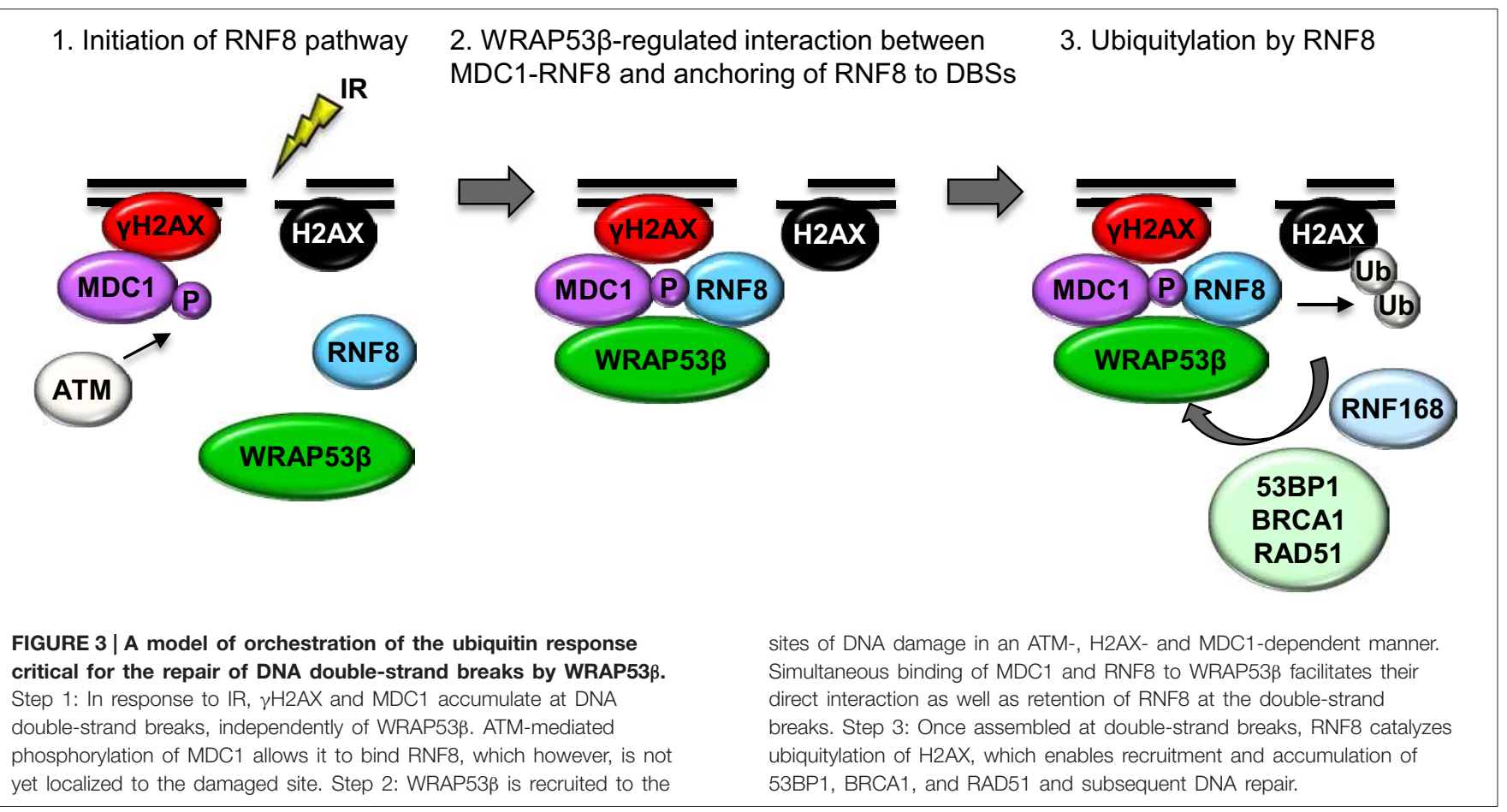

(Zhang et al., 2012a). Moreover, knockdown of WRAP53 $\beta$ in cancer cells reduced the size of the tumors formed when these are grafted into mice (Sun et al., 2014).

The role of WRAP53 $\beta$ in telomere elongation can at least partially explain its oncogenic properties, since re-activation of telomerase is what immortalizes $90 \%$ of all human cancer (Kyo and Inoue, 2002). At the same time, knockdown of WRAP53 $\beta$ in cancer cells induces apoptosis within $48-72 \mathrm{~h}$, whereas knockdown of telomerase enhances cell death only after several weeks in culture (Shammas et al., 2005). The observations that inactivating mutations in both alleles of WRAP $53 \beta$ causes dyskeratosis congenita, indicates that this protein acts as tumor suppressor, rather than an oncogene.

Indeed, with its complex roles in a number of cellular processes, WRAP53 $\beta$ may act as a tumor suppressor under certain conditions and as an oncogene in under others. The subcellular localization of WRAP $53 \beta$ may also explain some of its contradictory effects in tumor cells. For example, loss of nuclear, but not cytoplasmic WRAP53 $\beta$ is correlated survival and resistance to radiotherapy in patients with head and neck cancer (Garvin et al., 2015). Thus, the levels of this protein in the nucleus and cytoplasm must be considered separately in connection with patient prognosis.

Single nucleotide polymorphisms (SNPs) in the WRAP53 gene have been linked to an increased risk for breast and ovarian cancer (Garcia-Closas et al., 2007; Schildkraut et al., 2009; Medrek et al., 2013). One of these SNPs is also associated with defective DNA repair and hematotoxicity in workers exposed to benzene. SNPs in WRAP53 and four other genes (BLM, WRN, RAD51, and TP53), the products of which play key roles in DNA repair and maintenance of genomic integrity, especially via the HR pathway
(Lan et al., 2009), have been found to predispose to bezene toxicity. At this point, it is unclear how the SNPs in WRAP53 alter the functions of the WRAP $53 \beta$ protein.

In conclusion, WRAP $53 \beta$ dysfunction is associated with many diseases, but it is currently unknown whether accumulation of DNA damage and/or deficient DNA repair contributes to their etiology.

\section{WRAP53 $\beta$ Unwraps the Crosstalk between Cajal Bodies, RNA Processing, Telomeres and the DNA Damage Response}

DNA damaging agents, such as UV, cisplatin and IR all disrupt Cajal bodies and results in mislocalization of the marker protein coilin to microfoci and nucleoli. Moreover, coilin depletion enhances cell viability upon cisplatin treatment (Cioce et al., 2006; Boulon et al., 2010; Gilder et al., 2011). Such observations clearly reveal that the Cajal body responds to stress.

Several components of the Cajal body, including WRAP53 $\beta$, have been linked to the DNA damage response. Coilin interacts with $\mathrm{Ku} 70 / \mathrm{Ku} 80$ and inhibits NHEJ, presumably by preventing recruitment of the Ku proteins to DNA ends (Velma et al., 2010). SMN and Gemin2, members of the SMN complex, promote RAD51 assembly at DNA double-strand breaks and HR (Takaku et al., 2011). Interestingly, SMN interacts with methylated H3K79 in chromatin via its Tudor domain, a site known to target 53BP1 to DNA double-strand breaks (Huyen et al., 2004; Sabra et al., 2013). Notably, coilin also contains a Tudor domain that similar to SMN binds demethylarginine, as shown for Sm proteins (Tripsianes et al., 2011; Tapia et al., 2014). 
Certain factors involved in the DNA damage response are localized in Cajal bodies. For instance in Drosophila, following auto-modification, PARP translocates from chromatin to Cajal bodies (Kotova et al., 2009) and WRAP53 $\beta$ might also shuttle between these same two compartments. Furthermore, the SUMO E3 ligase PIAS4 (also known as PIAS $\gamma$ ), which accumulates at DNA double-strand breaks and is required for efficient RNF8mediated ubiquitylation at sites of DNA damage, is present in the Cajal body (Sun et al., 2005; Galanty et al., 2009). A number of large-scale screens for factors involved in the DNA damage response have revealed an enrichment of proteins involved in RNA processing, although their exact involvement is not yet understood (Li and Manley, 2005; Montecucco and Biamonti, 2013).

Only future investigations can reveal whether specific components of the Cajal body contribute to DNA repair, including repair events with which WRAP53 $\beta$ is associated. Moreover, the impact of the RNA-related activities of WRAP $53 \beta$ on the DNA damage response and/or the phenotypes associated with a deficiency in this protein remains to be determined. It is also unknown whether cells of patients with spinal muscular atrophy exhibit elevated DNA damage or deficient DNA repair. In any case, since coilin depletion does not disrupt DNA repair (Henriksson et al., 2014), maintenance of the structure of Cajal body is not linked directly to this process.

Telomeres represent an important additional link between WRAP $53 \beta$, Cajal bodies and the DNA damage response. DNA repair proteins are present on both functional and dysfunctional telomeres. In the case of functional telomeres, these factors promote homeostasis and prevent end-joining events. For example, DNA-PKcs appear to promote telomere capping, thereby attenuating telomere fusion (D’adda Di Fagagna et al., 2004). Moreover, Ku70/80 interacts directly with TERC to promote telomere maintenance (Ting et al., 2005). Dysfunctional, uncapped telomeres are recognized as DNA double-strand breaks by the DNA damage response, resulting in the assembly of repair factors into local telomere dysfunction-induced foci (TIFs) (Takai et al., 2003). HR and NHEJ at such sites gives rise to chromosome fusions and genomic instability, demonstrating that DNA repair at the wrong place can result in genomic instability. For example, RNF8 promotes the assembly of repair proteins at telomeres by ubiquitylating their ends, thereby facilitating chromosome fusion in cases of telomere dysfunction (Peuscher and Jacobs, 2011). Furthermore, 53BP1 increases the mobility of dysfunctional telomeres, bringing chromosomal ends into close proximity and thereby allowing NHEJ (Dimitrova et al., 2008). The findings that WRAP53 $\beta$ is involved in the recruitment of both RNF8/53BP1 to DNA doublestrand breaks and telomerase to telomeres raises the interesting possibility that WRAP $53 \beta$ regulate these processes via a common mechanism.

Telomerase-deficient ALT cells are characterized by very long and heterogeneous telomeres maintained by HR. In analogy to the role of Cajal bodies in telomerase-dependent telomere elongation (Jady et al., 2006; Tomlinson et al., 2006), a specific subpopulation of telomere-associated PML bodies has been proposed to promote the recombination in ALT cells. In addition to the conventional components of the PML body, these
ALT-associated PML bodies contain many proteins involved in the DNA damage response (Brault and Autexier, 2011). NBS1 is essential for their assembly: depletion of this protein leads to smaller number of ALT-associated PML bodies and telomere shortening in ALT-cells, but has no such effect on telomerase-positive cells (Wu et al., 2003; Zhong et al., 2007). Such observations indicate an intriguing link between nuclear body compartmentalization, telomere elongation and DNA damage response proteins.

\section{Concluding Remarks and Future Perspectives}

All of the functions described for WRAP53 $\beta$ involve the recruitment and proper targeting of factors to specific cellular sites (Figure 4). This protein binds the SMN complex in the cytoplasm and subsequently promotes its entry into the nucleus and localization to Cajal bodies. Patients with spinal muscular atrophy exhibit defective binding of WRAP53 $\beta$ to SMN, as well as reduced accumulation of SMN in Cajal bodies (Mahmoudi et al., 2010). Moreover, WRAP53 $\beta$ regulates telomerase localization to Cajal bodies, as well as to telomeres, and disruption of this trafficking causes dyskeratosis congenita (Venteicher et al., 2009; Zhong et al., 2011).

In addition, WRAP $53 \beta$ binds scaRNAs and promotes their localization to Cajal bodies (Tycowski et al., 2009). Finally, this protein binds the E3 ligase RNF8, facilitating its interaction with MDC1, which is required for its proper localization to DNA breaks and downstream repair events (Henriksson et al., 2014). Clearly, WRAP53 $\beta$ is as an essential scaffold protein that interacts with many types of RNA and protein, contributing both to their intracellular trafficking and interaction with other factors. However, it remains to be determined whether other Cajal body components also play a role in DNA repair, including repair associated with WRAP $53 \beta$.

The discovery that that inherited mutations in WRAP53 causes the syndrome dyskeratosis congenita, which predisposes

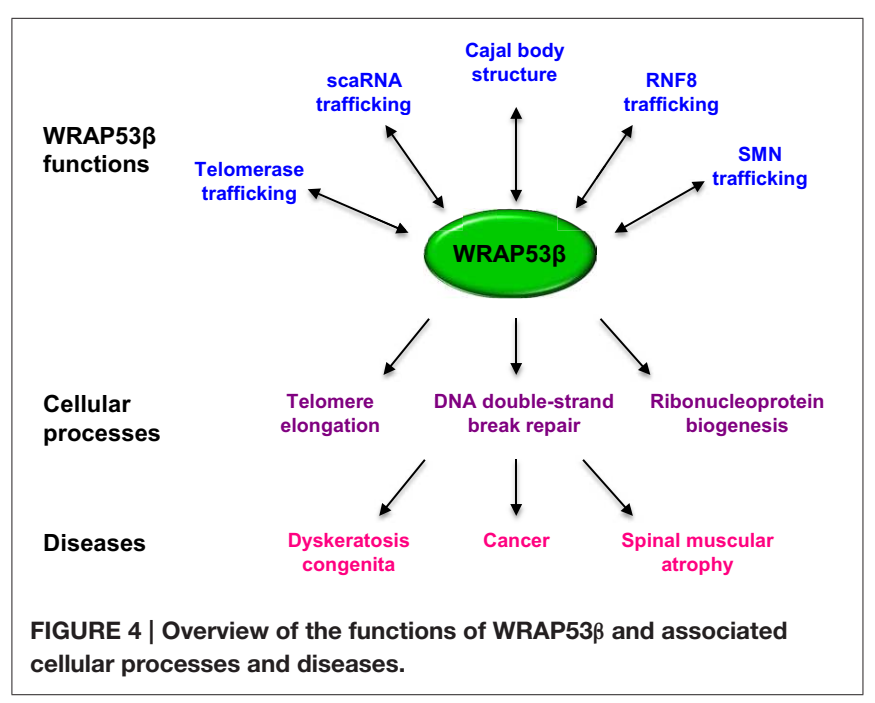


for cancer, suggests that this is a tumor suppressor gene. However, WRAP $53 \beta$ also possesses oncogenic properties and can be a potential target of cancer therapy (Mahmoudi et al., 2011). Disruption of Cajal bodies is expected to decrease production of mature snRNPs, resulting in inefficient splicing, and inhibitors of the spliceosome have shown anti-tumor activities (Van Alphen et al., 2009). In addition, deficient WRAP53 $\beta$-mediated trafficking of telomerase results in telomere shortening, both in vitro and in vivo (Venteicher et al., 2009). Moreover, the pathways involved in DNA repair are also targets for cancer therapy, either directly or in combination with DNA-damaging agents (Helleday et al., 2008). Further insights into the physiological roles of WRAP53 $\beta$

\section{References}

Artandi, S. E., and Depinho, R. A. (2010). Telomeres and telomerase in cancer. Carcinogenesis 31, 9-18. doi: 10.1093/carcin/bgp268

Ballew, B. J., and Savage, S. A. (2013). Updates on the biology and management of dyskeratosis congenita and related telomere biology disorders. Expert Rev. Hematol. 6, 327-337. doi: 10.1586/ehm.13.23

Bellodi, C., Mcmahon, M., Contreras, A., Juliano, D., Kopmar, N., Nakamura, T., et al. (2013). H/ACA small RNA dysfunctions in disease reveal key roles for noncoding RNA modifications in hematopoietic stem cell differentiation. Cell Rep. 3, 1493-1502. doi: 10.1016/j.celrep.2013.04.030

Boulon, S., Westman, B. J., Hutten, S., Boisvert, F. M., and Lamond, A. I. (2010). The nucleolus under stress. Mol. Cell 40, 216-227. doi: 10.1016/j.molcel.2010.09.024

Brault, M. E., and Autexier, C. (2011). Telomeric recombination induced by dysfunctional telomeres. Mol. Biol. Cell 22, 179-188. doi: 10.1091/mbc.E10-020173

Carvalho, T., Almeida, F., Calapez, A., Lafarga, M., Berciano, M. T., and CarmoFonseca, M. (1999). The spinal muscular atrophy disease gene product, SMN: a link between snRNP biogenesis and the Cajal (coiled) body. J. Cell Biol. 147, 715-728. doi: 10.1083/jcb.147.4.715

Cauchi, R. J. (2010). SMN and Gemins: 'we are family' ... or are we?: insights into the partnership between Gemins and the spinal muscular atrophy disease protein SMN. Bioessays 32, 1077-1089. doi: 10.1002/bies.201000088

Chari, A., Golas, M. M., Klingenhager, M., Neuenkirchen, N., Sander, B., Englbrecht, C., et al. (2008). An assembly chaperone collaborates with the SMN complex to generate spliceosomal SnRNPs. Cell 135, 497-509. doi: 10.1016/j.cell.2008.09.020

Chen, Y., Deng, Z., Jiang, S., Hu, Q., Liu, H., Songyang, Z., et al. (2015). Human cells lacking coilin and Cajal bodies are proficient in telomerase assembly, trafficking and telomere maintenance. Nucleic Acids Res. 43, 385-395. doi: 10.1093/nar/gku1277

Cioce, M., Boulon, S., Matera, A. G., and Lamond, A. I. (2006). UV-induced fragmentation of Cajal bodies. J. Cell Biol. 175, 401-413. doi: 10.1083/jcb.200604099

Cioce, M., and Lamond, A. I. (2005). Cajal bodies: a long history of discovery. Annu. Rev. Cell Dev. Biol. 21, 105-131. doi: 10.1146/annurev.cellbio.20.010403.103738

Coady, T. H., and Lorson, C. L. (2011). SMN in spinal muscular atrophy and snRNP biogenesis. Wiley Interdiscip. Rev. RNA 2, 546-564. doi: 10.1002/wrna.76

D'adda Di Fagagna, F., Teo, S. H., and Jackson, S. P. (2004). Functional links between telomeres and proteins of the DNA-damage response. Genes Dev. 18, 1781-1799. doi: 10.1101/gad.1214504

Darzacq, X., Jady, B. E., Verheggen, C., Kiss, A. M., Bertrand, E., and Kiss, T. (2002). Cajal body-specific small nuclear RNAs: a novel class of 2'-Omethylation and pseudouridylation guide RNAs. EMBO J. 21, 2746-2756. doi: 10.1093/emboj/21.11.2746

Dimitrova, N., Chen, Y. C., Spector, D. L., and De Lange, T. (2008). 53BP1 promotes non-homologous end joining of telomeres by increasing chromatin mobility. Nature 456, 524-528. doi: 10.1038/nature07433 and its contribution to the development of cancer might be provided by transgenic animal models.

\section{Acknowledgments}

This work was supported by grants from the Swedish Cancer Society (Cancerfonden), the Swedish Research Foundation (VR), the Strategic Research Programme in Cancer (StratCan), The Association for International Cancer Research (AICR), the Swedish Childhood Cancer Society (Barncancerfonden), the Cancer Society of Stockholm (Cancerföreningen), Olle Engkvist Byggmästare foundation and the Karolinska Institutet.

Dokal, I. (2011). Dyskeratosis congenita. Hematology Am. Soc. Hematol. Educ Program 2011, 480-486. doi: 10.1182/asheducation-2011.1.480

Dundr, M., and Misteli, T. (2010). Biogenesis of nuclear bodies. Cold Spring Harb. Perspect. Biol. 2:a000711. doi: 10.1101/cshperspect.a000711

Durocher, D., and Jackson, S. P. (2001). DNA-PK, ATM and ATR as sensors of DNA damage: variations on a theme? Curr. Opin. Cell Biol. 13, 225-231. doi: 10.1016/S0955-0674(00)00201-5

Egan, E. D., and Collins, K. (2010). Specificity and stoichiometry of subunit interactions in the human telomerase holoenzyme assembled in vivo. Mol. Cell. Biol. 30, 2775-2786. doi: 10.1128/MCB.00151-10

Egan, E. D., and Collins, K. (2012). An enhanced H/ACA RNP assembly mechanism for human telomerase RNA. Mol. Cell. Biol. 32, 2428-2439. doi: 10.1128/MCB.00286-12

Farnebo, M. (2009). Wrap53, a novel regulator of p53. Cell Cycle 8, 2343-2346. doi: $10.4161 /$ cc.8.15.9223

Fischer, U., Liu, Q., and Dreyfuss, G. (1997). The SMN-SIP1 complex has an essential role in spliceosomal snRNP biogenesis. Cell 90, 1023-1029. doi: 10.1016/S0092-8674(00)80368-2

Freund, A., Zhong, F. L., Venteicher, A. S., Meng, Z., Veenstra, T. D., Frydman, J., et al. (2014). Proteostatic control of telomerase function through TRiC-mediated folding of TCAB1. Cell 159, 1389-1403. doi: 10.1016/j.cell.2014.10.059

Frey, M. R., Bailey, A. D., Weiner, A. M., and Matera, A. G. (1999). Association of snRNA genes with coiled bodies is mediated by nascent snRNA transcripts. Curr. Biol. 9, 126-135. doi: 10.1016/S0960-9822(99)80066-9

Frey, M. R., and Matera, A. G. (1995). Coiled bodies contain U7 small nuclear RNA and associate with specific DNA sequences in interphase human cells. Proc. Natl. Acad. Sci. U.S.A. 92, 5915-5919. doi: 10.1073/pnas.92.13.5915

Galanty, Y., Belotserkovskaya, R., Coates, J., Polo, S., Miller, K. M., and Jackson, S. P. (2009). Mammalian SUMO E3-ligases PIAS1 and PIAS4 promote responses to DNA double-strand breaks. Nature 462, 935-939. doi: 10.1038/nature08657

Gall, J. G. (2003). The centennial of the Cajal body. Nat. Rev. Mol. Cell Biol. 4, 975-980. doi: 10.1038/nrm1262

Gao, L., Frey, M. R., and Matera, A. G. (1997). Human genes encoding U3 snRNA associate with coiled bodies in interphase cells and are clustered on chromosome 17p11.2 in a complex inverted repeat structure. Nucleic Acids Res. 25, 4740-4747. doi: 10.1093/nar/25.23.4740

Garcia-Closas, M., Kristensen, V., Langerod, A., Qi, Y., Yeager, M., Burdett, L., et al. (2007). Common genetic variation in TP53 and its flanking genes, WDR79 and ATP1B2, and susceptibility to breast cancer. Int. J. Cancer 121, 2532-2538. doi: 10.1002/ijc.22985

Garvin, S., Tiefenbock, K., Farnebo, L., Thunell, L. K., Farnebo, M., and Roberg, K. (2015). Nuclear expression of WRAP53beta is associated with a positive response to radiotherapy and improved overall survival in patients with head and neck squamous cell carcinoma. Oral Oncol. 51, 24-30. doi: 10.1016/j.oraloncology.2014.10.003

Gilder, A. S., Do, P. M., Carrero, Z. I., Cosman, A. M., Broome, H. J., Velma, V., et al. (2011). Coilin participates in the suppression of RNA polymerase I in response to cisplatin-induced DNA damage. Mol. Biol. Cell 22, 1070-1079. doi: 10.1091/mbc.E10-08-0731 
Gubitz, A. K., Feng, W., and Dreyfuss, G. (2004). The SMN complex. Exp. Cell Res. 296, 51-56. doi: 10.1016/j.yexcr.2004.03.022

Gu, B. W., Bessler, M., and Mason, P. J. (2008). A pathogenic dyskerin mutation impairs proliferation and activates a DNA damage response independent of telomere length in mice. Proc. Natl. Acad. Sci. U.S.A. 105, 10173-10178. doi: 10.1073/pnas.0803559105

Hebert, M. D., and Matera, A. G. (2000). Self-association of coilin reveals a common theme in nuclear body localization. Mol. Biol. Cell 11, 4159-4171. doi: $10.1091 / \mathrm{mbc} .11 .12 .4159$

Helleday, T., Petermann, E., Lundin, C., Hodgson, B., and Sharma, R. A. (2008). DNA repair pathways as targets for cancer therapy. Nat. Rev. Cancer 8, 193-204. doi: $10.1038 / \mathrm{nrc} 2342$

Henriksson, S., Rassoolzadeh, H., Hedstrom, E., Coucoravas, C., Julner, A., Goldstein, M., et al. (2014). The scaffold protein WRAP53beta orchestrates the ubiquitin response critical for DNA double-strand break repair. Genes Dev. 28, 2726-2738. doi: 10.1101/gad.246546.114

Huen, M. S., Grant, R., Manke, I., Minn, K., Yu, X., Yaffe, M. B., et al. (2007). RNF8 transduces the DNA-damage signal via histone ubiquitylation and checkpoint protein assembly. Cell 131, 901-914. doi: 10.1016/j.cell.2007.09.041

Huyen, Y., Zgheib, O., Ditullio, R. A. Jr., Gorgoulis, V. G., Zacharatos, P., Petty, T. J., et al. (2004). Methylated lysine 79 of histone H3 targets 53BP1 to DNA double-strand breaks. Nature 432, 406-411. doi: 10.1038/nature03114

Jady, B. E., Darzacq, X., Tucker, K. E., Matera, A. G., Bertrand, E., and Kiss, T. (2003). Modification of Sm small nuclear RNAs occurs in the nucleoplasmic Cajal body following import from the cytoplasm. EMBO J. 22, 1878-1888. doi: 10.1093/emboj/cdg187

Jady, B. E., Ketele, A., and Kiss, T. (2012). Human intron-encoded Alu RNAs are processed and packaged into Wdr79-associated nucleoplasmic box H/ACA RNPs. Genes Dev. 26, 1897-1910. doi: 10.1101/gad.197467.112

Jady, B. E., Richard, P., Bertrand, E., and Kiss, T. (2006). Cell cycle-dependent recruitment of telomerase RNA and Cajal bodies to human telomeres. Mol. Biol. Cell 17, 944-954. doi: 10.1091/mbc.E05-09-0904

Kaiser, T. E., Intine, R. V., and Dundr, M. (2008). De novo formation of a subnuclear body. Science 322, 1713-1717. doi: 10.1126/science.1165216

Kiss, T. (2002). Small nucleolar RNAs: an abundant group of noncoding RNAs with diverse cellular functions. Cell 109, 145-148. doi: 10.1016/S00928674(02)00718-3

Kiss, T., Fayet, E., Jady, B. E., Richard, P., and Weber, M. (2006). Biogenesis and intranuclear trafficking of human box C/D and H/ACA RNPs. Cold Spring Harb. Symp. Quant. Biol. 71, 407-417. doi: 10.1101/sqb.2006.71.025

Kolas, N. K., Chapman, J. R., Nakada, S., Ylanko, J., Chahwan, R., Sweeney, F. D., et al. (2007). Orchestration of the DNA-damage response by the RNF8 ubiquitin ligase. Science 318, 1637-1640. doi: 10.1126/science.1150034

Kotova, E., Jarnik, M., and Tulin, A. V. (2009). Poly (ADP-ribose) polymerase 1 is required for protein localization to Cajal body. PLoS Genet. 5:e1000387. doi: 10.1371/journal.pgen.1000387

Kyo, S., and Inoue, M. (2002). Complex regulatory mechanisms of telomerase activity in normal and cancer cells: how can we apply them for cancer therapy? Oncogene 21, 688-697. doi: 10.1038/sj.onc.1205163

Lan, Q., Zhang, L., Shen, M., Jo, W. J., Vermeulen, R., Li, G., et al. (2009). Large-scale evaluation of candidate genes identifies associations between DNA repair and genomic maintenance and development of benzene hematotoxicity. Carcinogenesis 30, 50-58. doi: 10.1093/carcin/bgn249

Lefebvre, S., Burlet, P., Liu, Q., Bertrandy, S., Clermont, O., Munnich, A., et al. (1997). Correlation between severity and SMN protein level in spinal muscular atrophy. Nat. Genet. 16, 265-269. doi: 10.1038/ng0797-265

Lemm, I., Girard, C., Kuhn, A. N., Watkins, N. J., Schneider, M., Bordonne, R., et al. (2006). Ongoing $\mathrm{U}$ snRNP biogenesis is required for the integrity of Cajal bodies. Mol. Biol. Cell 17, 3221-3231. doi: 10.1091/mbc.E06-03-0247

Li, X., and Manley, J. L. (2005). Inactivation of the SR protein splicing factor ASF/SF2 results in genomic instability. Cell 122, 365-378. doi: 10.1016/j.cell.2005.06.008

Machyna, M., Heyn, P., and Neugebauer, K. M. (2013). Cajal bodies: where form meets function. Wiley Interdiscip. Rev. RNA 4, 17-34. doi: 10.1002/wrna.1139

Mahmoudi, S., Henriksson, S., Corcoran, M., Mendez-Vidal, C., Wiman, K. G., and Farnebo, M. (2009). Wrap53, a natural p53 antisense transcript required for p53 induction upon DNA damage. Mol. Cell 33, 462-471. doi: 10.1016/j.molcel.2009.01.028
Mahmoudi, S., Henriksson, S., Farnebo, L., Roberg, K., and Farnebo, M. (2011). WRAP53 promotes cancer cell survival and is a potential target for cancer therapy. Cell Death Dis. 2, e114. doi: 10.1038/cddis.2010.90

Mahmoudi, S., Henriksson, S., Weibrecht, I., Smith, S., Soderberg, O., Stromblad, S., et al. (2010). WRAP53 is essential for Cajal body formation and for targeting the survival of motor neuron complex to Cajal bodies. PLoS Biol. 8:e1000521. doi: 10.1371/journal.pbio.1000521

Mailand, N., Bekker-Jensen, S., Faustrup, H., Melander, F., Bartek, J., Lukas, C., et al. (2007). RNF8 ubiquitylates histones at DNA double-strand breaks and promotes assembly of repair proteins. Cell 131, 887-900. doi: 10.1016/j.cell.2007.09.040

Marnef, A., Richard, P., Pinzon, N., and Kiss, T. (2014). Targeting vertebrate intron-encoded box C/D 2'-O-methylation guide RNAs into the Cajal body. Nucleic Acids Res. 42, 6616-6629. doi: 10.1093/nar/gku287

Matera, A. G., and Wang, Z. (2014). A day in the life of the spliceosome. Nat. Rev. Mol. Cell Biol. 15, 108-121. doi: 10.1038/nrm3742

Medrek, K., Magnowski, P., Masojc, B., Chudecka-Glaz, A., Torbe, B., Menkiszak, J., et al. (2013). Association of common WRAP 53 variant with ovarian cancer risk in the Polish population. Mol. Biol. Rep. 40, 2145-2147. doi: 10.1007/s11033-012-2273-9

Mitchell, J. R., Cheng, J., and Collins, K. (1999). A box H/ACA small nucleolar RNA-like domain at the human telomerase RNA $3^{\prime}$ end. Mol. Cell. Biol. 19, 567-576.

Mochizuki, Y., He, J., Kulkarni, S., Bessler, M., and Mason, P. J. (2004). Mouse dyskerin mutations affect accumulation of telomerase RNA and small nucleolar RNA, telomerase activity, and ribosomal RNA processing. Proc. Natl. Acad. Sci. U.S.A. 101, 10756-10761. doi: 10.1073/pnas.0402560101

Montecucco, A., and Biamonti, G. (2013). Pre-mRNA processing factors meet the DNA damage response. Front. Genet. 4:102. doi: 10.3389/fgene.2013.00102

Novotny, I., Blazikova, M., Stanek, D., Herman, P., and Malinsky, J. (2011). In vivo kinetics of U4/U6.U5 tri-snRNP formation in Cajal bodies. Mol. Biol. Cell 22, 513-523. doi: 10.1091/mbc.E10-07-0560

Oskoui, M., Levy, G., Garland, C. J., Gray, J. M., O’hagen, J., De Vivo, D. C., et al. (2007). The changing natural history of spinal muscular atrophy type 1. Neurology 69, 1931-1936. doi: 10.1212/01.wnl.0000290830.40544.b9

Pellizzoni, L., Yong, J., and Dreyfuss, G. (2002). Essential role for the SMN complex in the specificity of snRNP assembly. Science 298, 1775-1779. doi: $10.1126 /$ science. 1074962

Peuscher, M. H., and Jacobs, J. J. (2011). DNA-damage response and repair activities at uncapped telomeres depend on RNF8. Nat. Cell Biol. 13, 1139-1145. doi: $10.1038 / \mathrm{ncb} 2326$

Platani, M., Goldberg, I., Swedlow, J. R., and Lamond, A. I. (2000). In vivo analysis of Cajal body movement, separation, and joining in live human cells. J. Cell Biol. 151, 1561-1574. doi: 10.1083/jcb.151.7.1561

Polo, S. E., and Jackson, S. P. (2011). Dynamics of DNA damage response proteins at DNA breaks: a focus on protein modifications. Genes Dev. 25, 409-433. doi: 10.1101/gad.2021311

Rao, X., Huang, D., Sui, X., Liu, G., Song, X., Xie, J., et al. (2014). Overexpression of WRAP53 is associated with development and progression of esophageal squamous cell carcinoma. PLOS ONE 9:e91670. doi: 10.1371/journal.pone. 0091670

Richard, P., Darzacq, X., Bertrand, E., Jady, B. E., Verheggen, C., and Kiss, T. (2003). A common sequence motif determines the Cajal bodyspecific localization of box H/ACA scaRNAs. EMBO J. 22, 4283-4293. doi: $10.1093 /$ emboj/cdg394

Ruggero, D., Grisendi, S., Piazza, F., Rego, E., Mari, F., Rao, P. H., et al. (2003). Dyskeratosis congenita and cancer in mice deficient in ribosomal RNA modification. Science 299, 259-262. doi: 10.1126/science.1079447

Sabra, M., Texier, P., El Maalouf, J., and Lomonte, P. (2013). The Tudor protein survival motor neuron (SMN) is a chromatin-binding protein that interacts with methylated lysine 79 of histone H3. J. Cell Sci. 126, 3664-3677. doi: $10.1242 /$ jcs. 126003

Saldana-Meyer, R., Gonzalez-Buendia, E., Guerrero, G., Narendra, V., Bonasio, R., Recillas-Targa, F., et al. (2014). CTCF regulates the human p53 gene through direct interaction with its natural antisense transcript, Wrap53. Genes Dev. 28, 723-734. doi: 10.1101/gad.236869.113

Schildkraut, J. M., Goode, E. L., Clyde, M. A., Iversen, E. S., Moorman, P. G., Berchuck, A., et al. (2009). Single nucleotide polymorphisms in the TP53 
region and susceptibility to invasive epithelial ovarian cancer. Cancer Res. 69, 2349-2357. doi: 10.1158/0008-5472.CAN-08-2902

Shammas, M. A., Koley, H., Batchu, R. B., Bertheau, R. C., Protopopov, A., Munshi, N. C., et al. (2005). Telomerase inhibition by siRNA causes senescence and apoptosis in Barrett's adenocarcinoma cells: mechanism and therapeutic potential. Mol. Cancer 4, 24. doi: 10.1186/1476-4598-4-24

Shevtsov, S. P., and Dundr, M. (2011). Nucleation of nuclear bodies by RNA. Nat. Cell Biol. 13, 167-173. doi: 10.1038/ncb2157

Stirnimann, C. U., Petsalaki, E., Russell, R. B., and Muller, C. W. (2010). WD40 proteins propel cellular networks. Trends Biochem. Sci. 35, 565-574. doi: 10.1016/j.tibs.2010.04.003

Stucki, M., Clapperton, J. A., Mohammad, D., Yaffe, M. B., Smerdon, S. J., and Jackson, S. P. (2005). MDC1 directly binds phosphorylated histone H2AX to regulate cellular responses to DNA double-strand breaks. Cell 123, 1213-1226. doi: 10.1016/j.cell.2005.09.038

Sun, C. K., Luo, X. B., Gou, Y. P., Hu, L., Wang, K., Li, C., et al. (2014). TCAB1: a potential target for diagnosis and therapy of head and neck carcinomas. Mol. Cancer 13:180. doi: 10.1186/1476-4598-13-180

Sun, J., Xu, H., Subramony, S. H., and Hebert, M. D. (2005). Interactions between coilin and PIASy partially link Cajal bodies to PML bodies. J. Cell Sci. 118, 4995-5003. doi: 10.1242/jcs.02613

Takai, H., Smogorzewska, A., and De Lange, T. (2003). DNA damage foci at dysfunctional telomeres. Curr. Biol. 13, 1549-1556. doi: 10.1016/S09609822(03)00542-6

Takaku, M., Tsujita, T., Horikoshi, N., Takizawa, Y., Qing, Y., Hirota, K., et al. (2011). Purification of the human SMN-GEMIN2 complex and assessment of its stimulation of RAD51-mediated DNA recombination reactions. Biochemistry 50, 6797-6805. doi: 10.1021/bi200828g

Tapia, O., Bengoechea, R., Palanca, A., Arteaga, R., Val-Bernal, J. F., Tizzano, E. F., et al. (2012). Reorganization of Cajal bodies and nucleolar targeting of coilin in motor neurons of type I spinal muscular atrophy. Histochem. Cell Biol. 137, 657-667. doi: 10.1007/s00418-012-0921-8

Tapia, O., Lafarga, V., Bengoechea, R., Palanca, A., Lafarga, M., and Berciano, M. T. (2014). The SMN Tudor SIM-like domain is key to SmD1 and coilin interactions and to Cajal body biogenesis. J. Cell Sci. 127, 939-946. doi: $10.1242 /$ jcs. 138537

Ting, N. S., Yu, Y., Pohorelic, B., Lees-Miller, S. P., and Beattie, T. L. (2005). Human Ku70/80 interacts directly with hTR, the RNA component of human telomerase. Nucleic Acids Res. 33, 2090-2098. doi: 10.1093/nar/gki342

Tomlinson, R. L., Ziegler, T. D., Supakorndej, T., Terns, R. M., and Terns, M. P. (2006). Cell cycle-regulated trafficking of human telomerase to telomeres. Mol. Biol. Cell 17, 955-965. doi: 10.1091/mbc.E05-09-0903

Trahan, C., and Dragon, F. (2009). Dyskeratosis congenita mutations in the H/ACA domain of human telomerase RNA affect its assembly into a pre-RNP. RNA 15, 235-243. doi: 10.1261/rna.1354009

Tripsianes, K., Madl, T., Machyna, M., Fessas, D., Englbrecht, C., Fischer, U., et al. (2011). Structural basis for dimethylarginine recognition by the Tudor domains of human SMN and SPF30 proteins. Nat. Struct. Mol. Biol. 18, 1414-1420. doi: 10.1038/nsmb. 2185

Tycowski, K. T., Shu, M. D., Kukoyi, A., and Steitz, J. A. (2009). A conserved WD40 protein binds the Cajal body localization signal of scaRNP particles. Mol. Cell 34, 47-57. doi: 10.1016/j.molcel.2009.02.020

Van Alphen, R. J., Wiemer, E. A., Burger, H., and Eskens, F. A. (2009). The spliceosome as target for anticancer treatment. Br. J. Cancer 100, 228-232. doi: $10.1038 /$ sj.bjc. 6604801
Velma, V., Carrero, Z. I., Cosman, A. M., and Hebert, M. D. (2010). Coilin interacts with Ku proteins and inhibits in vitro non-homologous DNA end joining. FEBS Lett. 584, 4735-4739. doi: 10.1016/j.febslet.2010.11.004

Venteicher, A. S., Abreu, E. B., Meng, Z., Mccann, K. E., Terns, R. M., Veenstra, T. D., et al. (2009). A human telomerase holoenzyme protein required for Cajal body localization and telomere synthesis. Science 323, 644-648. doi: $10.1126 /$ science. 1165357

Vulliamy, T. J., Kirwan, M. J., Beswick, R., Hossain, U., Baqai, C., Ratcliffe, A., et al. (2011). Differences in disease severity but similar telomere lengths in genetic subgroups of patients with telomerase and shelterin mutations. PLoS ONE 6:e24383. doi: 10.1371/journal.pone.0024383

Whittom, A. A., Xu, H., and Hebert, M. D. (2008). Coilin levels and modifications influence artificial reporter splicing. Cell. Mol. Life Sci. 65, 1256-1271. doi: 10.1007/s00018-008-7587-3

Wu, G., Jiang, X., Lee, W. H., and Chen, P. L. (2003). Assembly of functional ALT-associated promyelocytic leukemia bodies requires Nijmegen Breakage Syndrome 1. Cancer Res. 63, 2589-2595.

$\mathrm{Xu}, \mathrm{C}$., and Min, J. (2011). Structure and function of WD40 domain proteins. Protein Cell 2, 202-214. doi: 10.1007/s13238-011-1018-1

Zaug, A. J., Crary, S. M., Jesse Fioravanti, M., Campbell, K., and Cech, T. R. (2013). Many disease-associated variants of hTERT retain high telomerase enzymatic activity. Nucleic Acids Res. 41, 8969-8978. doi: 10.1093/nar/ gkt653

Zhang, H., Wang, D. W., Adell, G., and Sun, X. F. (2012a). WRAP53 is an independent prognostic factor in rectal cancer- a study of Swedish clinical trial of preoperative radiotherapy in rectal cancer patients. BMC Cancer 12:294. doi: 10.1186/1471-2407-12-294

Zhang, Y., Morimoto, K., Danilova, N., Zhang, B., and Lin, S. (2012b). Zebrafish models for dyskeratosis congenita reveal critical roles of p53 activation contributing to hematopoietic defects through RNA processing. PLoS ONE 7:e30188. doi: 10.1371/journal.pone.0030188

Zhang, Z., Lotti, F., Dittmar, K., Younis, I., Wan, L., Kasim, M., et al. (2008). SMN deficiency causes tissue-specific perturbations in the repertoire of snRNAs and widespread defects in splicing. Cell 133, 585-600. doi: 10.1016/j.cell.2008.03.031

Zhong, F., Savage, S. A., Shkreli, M., Giri, N., Jessop, L., Myers, T. et al. (2011). Disruption of telomerase trafficking by TCAB1 mutation causes dyskeratosis congenita. Genes Dev. 25, 11-16. doi: 10.1101/gad. 2006411

Zhong, Z. H., Jiang, W. Q., Cesare, A. J., Neumann, A. A., Wadhwa, R., and Reddel, R. R. (2007). Disruption of telomere maintenance by depletion of the MRE11/RAD50/NBS1 complex in cells that use alternative lengthening of telomeres. J. Biol. Chem. 282, 29314-29322. doi: 10.1074/jbc.M7014 13200

Conflict of Interest Statement: The authors declare that the research was conducted in the absence of any commercial or financial relationships that could be construed as a potential conflict of interest.

Copyright $(0) 2015$ Henriksson and Farnebo. This is an open-access article distributed under the terms of the Creative Commons Attribution License (CC BY). The use, distribution or reproduction in other forums is permitted, provided the original author(s) or licensor are credited and that the original publication in this journal is cited, in accordance with accepted academic practice. No use, distribution or reproduction is permitted which does not comply with these terms. 